\title{
A Micro Mobile Robot with Suction Cups in the Abdominal Cavity for NOTES
}

\author{
Chika Hiroki and Wenwei Yu \\ Graduate School of Engineering, Chiba University \\ Japan
}

\section{Introduction}

NOTES (Natural Orifice Translumenal Endoscopic Surgery), in which forceps are put through a natural orifice, such as the mouth, anus or vagina, and a hole is cut at the site to reach intra-abdominal cavity. Because this surgery is able to minimize incision size and the amount of pain, thus greatly improve the quality of life of patients. Although the NOTES approach may hold tremendous potential, there are difficulties that should be overcome before this technique is introduced into clinical care. The most serious one is that since the distance from the surgeon's fingertip to the targeted site is generally longer than that of the usual endoscopic operations, manipulation of forceps is much more difficult, which brings more burdens on the surgeons; meanwhile, there are few surgical devices that could be specifically used for NOTES.

The aim of this study is to develop surgical devices that could facilitate high manipulability and high functionality (cut, hold tissues, hold camera) for NOTES.

The biggest issue when developing an device for NOTES support use is that it has to show both flexibility and rigidity. On one hand, in order to pass a long pathway (i.e., the esophagus) to reach a site (i.e., the stomach) it should be flexible enough. On the other hand, after reaching its target site (i.e., the abdominal cavity), it should show sufficient rigidity which could stay at the site steadily and perform its tasks, such as holding a camera for inspection, and/or a soft forceps in operations.

The first type expanded the traditional flexible endoscope for single port access surgery $(\mathrm{Xu}$. et. al., 2009), which has built-in camera, forceps, and electric scalpel, all folded in a small cylinder before and during insertion, then deployed after reaching its targeted site. This type of device owns sufficient flexibility, however, since the fulcrum of the manipulation (a point to provide support of manipulation) is outside the port, as the distance between the fulcrum and targeted site increases, its rigidity of system will be reduced by its inherent flexibility, and force will be even more difficult to transmitted to the endeffector usually located at the detail portion of the device.

The robot type goes to another extreme. The robot moves around the targeted site, after being inserted through the port. The fulcrum of manipulation is usually near the endeffector, thus the Robot Type usually has good manipulability. It has been reported that a wheeled surgical robot system could move on the surface of liver (Rentschler \& Reid, 2009). However, the mobile mechanism could not provide mobility to cover whole abdominal cavity for NOTES support usage. Moreover, not all the surface of inner organs 
are suitable as the movement plane. Sudden involuntary movement of inner organs in the abdominal cavity would be irresistible disturbance to robots. For the use of surgery support in the abdominal cavity, magnetic based mechanism has been employed (Lehman. et. al., 2008a, 2008b, 2008c, 2009; Dumpert, 2009). Generally, adhered to an outer magnet, a movable magnetic object inside the body cavity could be moved through moving the outer magnet. However, high magnet field needed (0.6T-2T) unavoidably gives strong constraint to surgical tools and devices, which increases cost of surgery. Moreover, the safety issues concerning long-term exposure to strong magnet field should also be carefully investigated.

Suction cup has been shown as an effective way to adhere to living organisms or biological objects, since it gives less damage to attaching surface. Suction effect to avian livers has been investigated in (Horie. et al, 2007), for developing a micro switchable sucker system. HeartLander (Patronik. et al, 2005a, 2005b, 2009), which was designed for moving on epicardium, moved using suction cups and a wire driven mechanism. It is recognized as the most successful mobile robotic system working in human body cavity. However, neither the mobility of the system, nor the adhesion to intraperitoneal environment were tested. The aim of this study was to construct a robotic system that can improve the manipulability and functionality for NOTES, using vacuum suction cups, moving on the peritoneum (the abdominal wall). The advantages of the robotic system, as well as the design details will be discussed in section 2 .

\section{Construction of the robot}

\subsection{Basic considerations and specification of the robot}

- Stable movement and surgery support actions.

Since the surface of the intraperitoneal organs, such as the large intestine and the stomach, is unstable due to peristalsis and other factors, in order to achieve stable movements and surgery support actions, we had to consider the other possibilities. In this study, we proposed using the peritoneum (the smooth serous membrane that lines the abdominal cavity) as the surface for moving in the abdominal cavity.

- $\quad$ Less damage to the internal environment and fewer electrical devices.

The effort to produce less damage to the internal environment (according to the issue discussed above, the peritoneum) and use fewer electrical devices is significantly important considering the robot's medical application. In this study, we employed vacuum suction as the means to attach to the peritoneum and devised a cable-driven mechanism to realize the relative movements of the two suction cups.

- $\quad$ Degree of freedom (D.O.F.) necessary for mobility and surgery support.

In order to move on the peritoneum and guide the forceps to the targeted sites, 3- D.O.F. movements, i.e., moving forward/backward, turning left/right and moving up/down, should be realized. Moving up/down is important because (i) when one of the suction cups is detached from the peritoneum for the relative movement, anti-gravity control is necessary; (ii) the peritoneum is not a flat plane - especially after being filled with gas (one procedure during laparoscopic surgery), the peritoneum turns to be a dome-like threedimensional (3-D) landscape; (iii) the elasticity of the peritoneum will increase the difference in elevation; and (iv) the robot should be able to clear the ramp when moving from the overtube to abdominal cavity. 
- $\quad$ Size and weight constraints.

While realizing the functions discussed above, there are design constraints that should be met, i.e., the robot should be small and light enough. The constraints come from the size of the overtube for endoscopic operation, and robot's load-bearing ability that depends on the sucking force, and the weight of the robot body, camera and flexible forceps. Considering the inner diameter of the overtube, the diameter of our robot should be limited to less than 16.5 [mm]. However, since the purpose of this study is to investigate the feasibility of the robot, the diametral size of the robot was set to $34[\mathrm{~mm}]$, according to the machining accuracy and parts currently available.

\subsection{The robot with suction cups developed}

Different with the other robots and devices using suction cups, the robot developed in our previous study moves in the abdominal cavity, hanging upside down from the abdominal wall and supports NOTES. The first prototype is shown in Fig. 1.

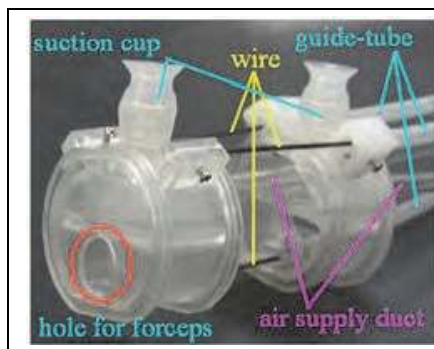

(a) mechanical structure

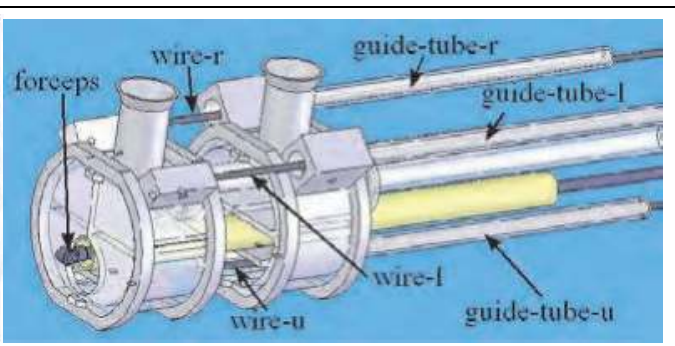

(b) 3-D illustration

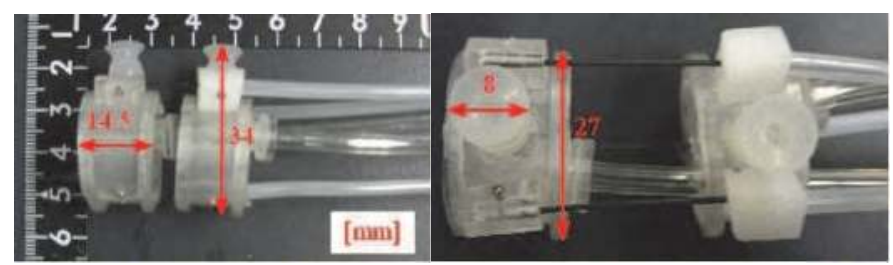

(c) side surface

(d) upper surface

Fig. 1. Construction of the robot

Three pairs of wires and guide-tubes were equipped to realize relative movement of the two suction cups, thus realizing the 3-D.O.F. movements for the robot. The three pairs of wires and guide-tubes, together with two air supply ducts, were contained in two housings (front and rear housings). Wires were fixed to the front housing and guide-tubes were fixed to the rear housing. In the front housing, there's a hole for loading and guiding forceps. The diametral size of robot is $34 \mathrm{~mm}$, bigger than the inner diameter of the overtube; after carefully re-inspecting the current design of the robot, we could have an optimistic view that the problem can be solved in the next version of prototype. The wire-u and the guidetube-u are equipped to enable the vertical movement of the robot (shown in Fig. 1). We adopted Ti-Ni alloy as wires for control of the front housing. 


\subsection{Control system}

Fig. 2 shows general view of the robot's control system.

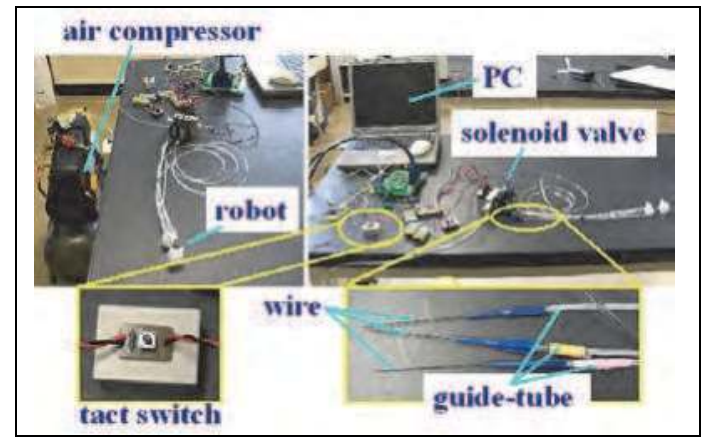

Fig. 2. Robot's control system

The block diagram for the robot control is shown in Fig. 3. Movement of three degrees of freedom could be realized by controlling the state transition between adsorption and release of the suction cups, as well as the relative displacement of the two housings (containing a suction cup in each).

The suction control was achieved by using a digital solenoid valve [ZX1103-K16LZ-EC; $\mathrm{SMC}$ ] that regulates the vacuum pressure generated by a compressor [0.75LP-75; Hitachi Industrial Equipment Systems], which generates air pressure up to $0.69 \mathrm{MPa}$. The valve can switch between adsorption and release of suction cups according to the command sent to it from output ports of a personal computer. Concretely, the negative pressure supplied from the compressor is controlled by an input voltage (ON: $12 \mathrm{v}$ or OFF: $0 \mathrm{v}$ ), which corresponds deaeration (for adsorption state) or insufflation (for release state) of the air to the suction cups. Moreover, the adsorption state could be detected by the pressure sensor in the valve, and sent back to PC for control.

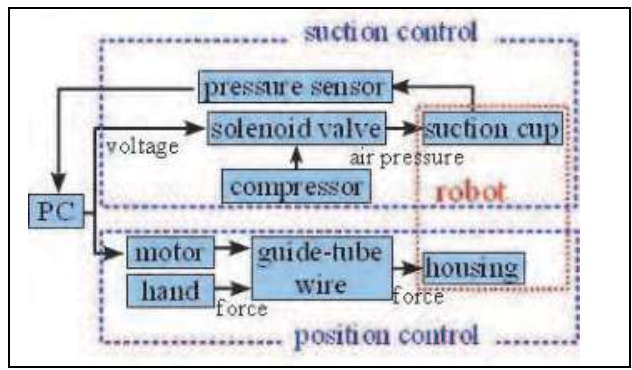

Fig. 3. Block diagram of the robot control

\subsection{Phase diagrams of movements}

1. Moving forward/backward

The phase diagram of moving forward is shown in Fig. 4(a), where a hatched circle means an adsorbed suction cup, whereas an open circle means a released one. It is obvious that, the motion could be divided into 5 phases, starting from an initial phase 0 (both suction cups 
absorb), releasing one suction cup and pushing forward (shown by an arrow marked with F) the wires (for moving the front suction cup) or the guide-tubes (for moving the rear suction cup), sequentially and repeatedly. Also the phase diagram of moving backward could be acquired by simply reversing the direction of force (arrows).

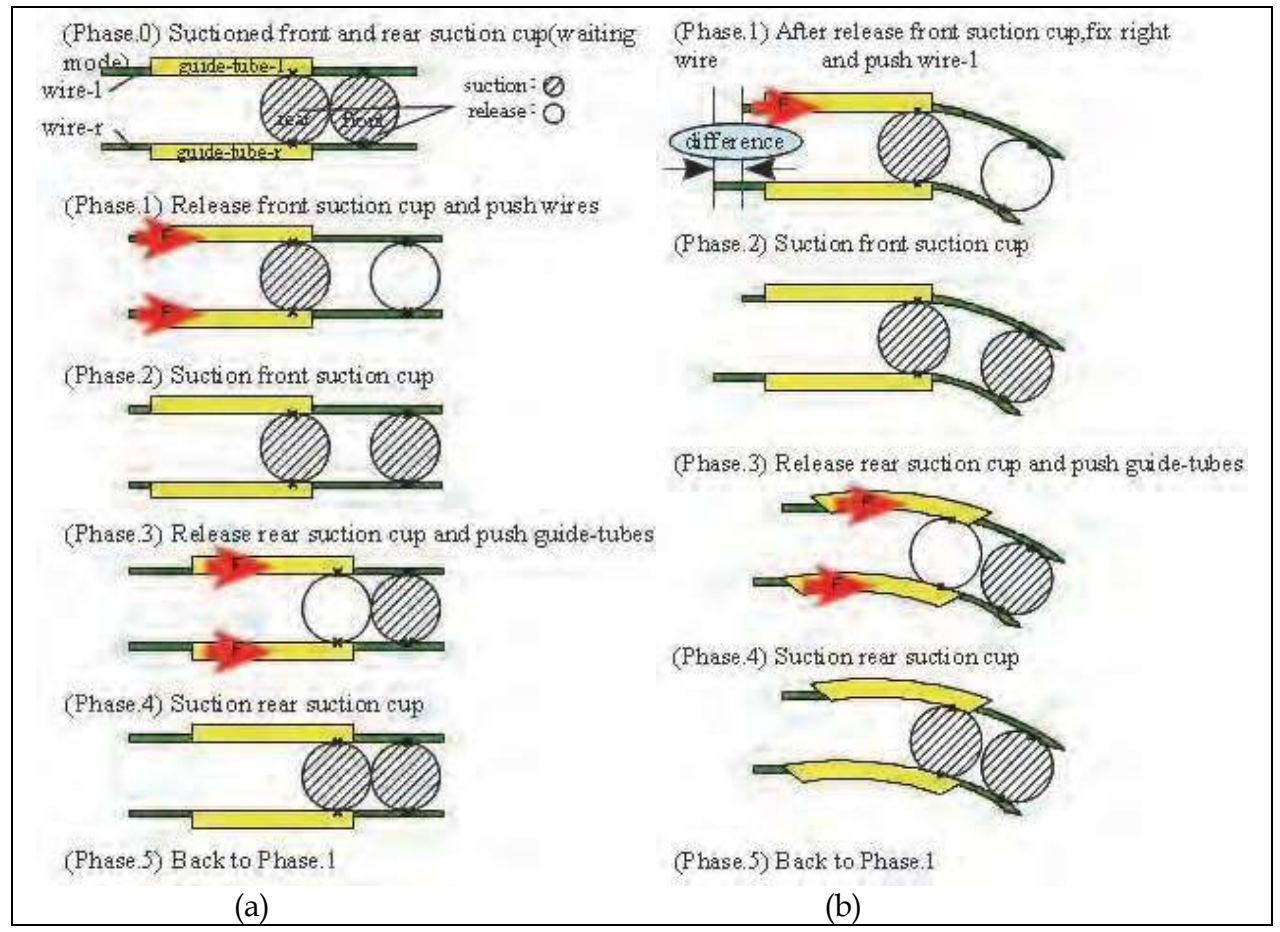

Fig. 4. Phase diagram (a) moving forward (b) turning right

\section{Turning left/right}

Turning motion is realized by making difference between the stretching-out length of left and right wires. The phase diagram of turning right is shown in Fig. 4(b). Different with moving forward motion, in phase 1 , in order to move the front housing right, the left wire was pushed out, while fixing the right wire length, thus, the left wire will bend towards right, and the front housing will turn right. Turning left could be achieved by making stretching-out length of right wire longer during phase 1. Except this making difference between the left and right stretching-out wire length, the suction control of turning motion is basically the same as that of moving forward.

3. Moving up/down

Vertical movement is also possible by making difference between the stretching-out length of upper wires (those two wires close to suction cups) and lower wire (one single wire) (Fig. 5). 


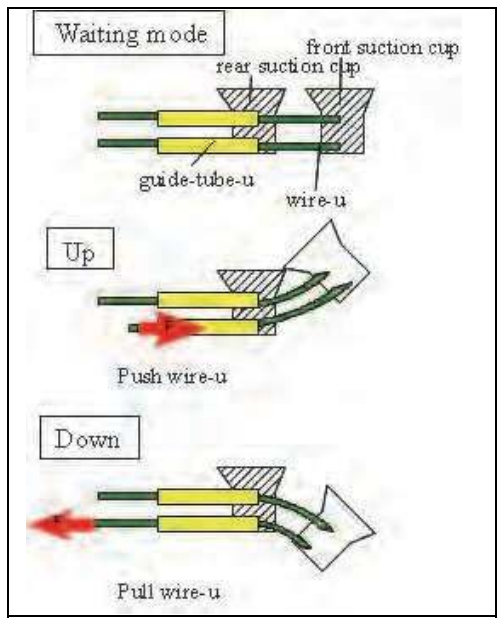

Fig. 5. Phase diagram of moving up/down

\subsection{Experiment with the first prototype}

The motions described in the last section were verified using the first prototype, by manual operation. The robot was operated to move on a piece of transparent film pasted onto a flat, level frame of a laparoscope operation simulation unit (Fig. 6).

It was confirmed that all the motions could be realized by manual operation. The forces needed to operate the robot will be shown in the next section. Moreover, even with a $50 \mathrm{~g}$ load, the robot could move forward. Fig. 7 shows the pictures of each phase of robot with $50 \mathrm{~g}$ load, in moving forward motion.

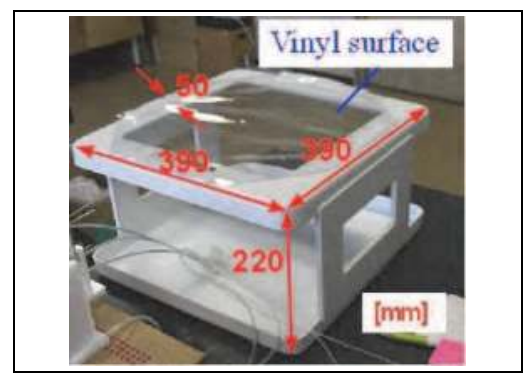

Fig. 6. Laparoscope operation simulation unit

\section{Automatic control system}

As shown before, with manual operation, the robot prototype could realize the movement designed, hanging upside down from a transparent film. However, the operation needs the manipulation of three wires and three guide-tubes independently, and sometimes several of them simultaneously. Therefore, it's complicated and difficult to operate the robot by one surgeon. Thus, it is necessary to develop an automation system that could operate the wires and guide-tubes automatically, as well as a user interface that could receive and translation 


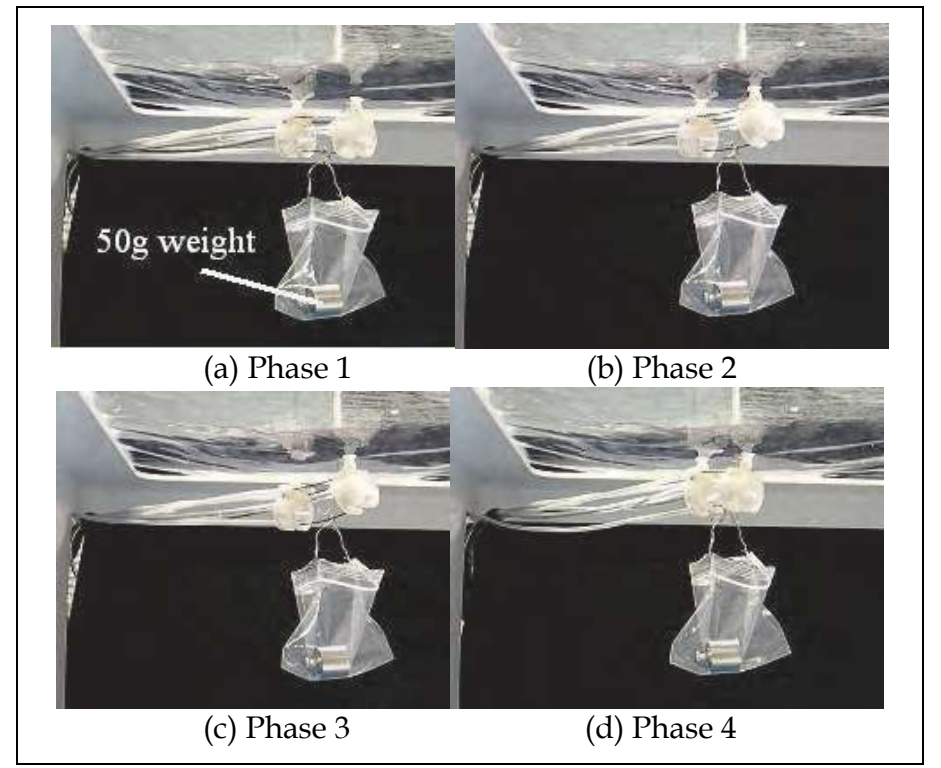

Fig. 7. Phase views of moving forward motion with a $50 \mathrm{~g}$ weight

the instruction from surgeons to the automation system. This section describes the such hardware and software for such a controller: a WGL controller (Wire and Guide-tube Length controller).

\subsection{Developing the WGL controller}

In order to adjust the length of wires and guide-tubes, the manipulation part should be able to 1) realize a push and pull linear motion with the stroke longer than $300 \mathrm{~mm}$, and with suitable axial forces; 2) guarantee independent linear motion of paired wire and guide-tube to be coaxial; 3) hold the wires and guide-tubes stably and fixedly without breaking the wires and guide-tubes. Besides, control algorithm should be developed to realize effective automatic manipulation.

In this section, we described our efforts to realize the WGL controller. We measured the force required to manipulate the wires and guide-tubes in a manual operation. Secondly, we developed a linear motion mechanism by using motors and timing belts. Thirdly, we designed a griping mechanism that is fixed to the timing belt and able to hold wires and guide-tubes. Finally, we proposed control algorithms using sensor information.

\subsubsection{Measurement of the force required to manipulate wire and guide-tube}

In order to develop the device which controls the length of wires and guide-tubes, it's necessary to measure how much force is actually required for operation. Then, we measured force required for push/pull of each wire and each guide-tube by using the force measurement system (Fig. 8(a)). We measured the forces of 4 operations of moving forward/backward and turning left/right 3 times each. Moreover, the force gauge as shown in Fig. 8(b) was used for the measurement (ZPS-DPU-50N; IMADA). 


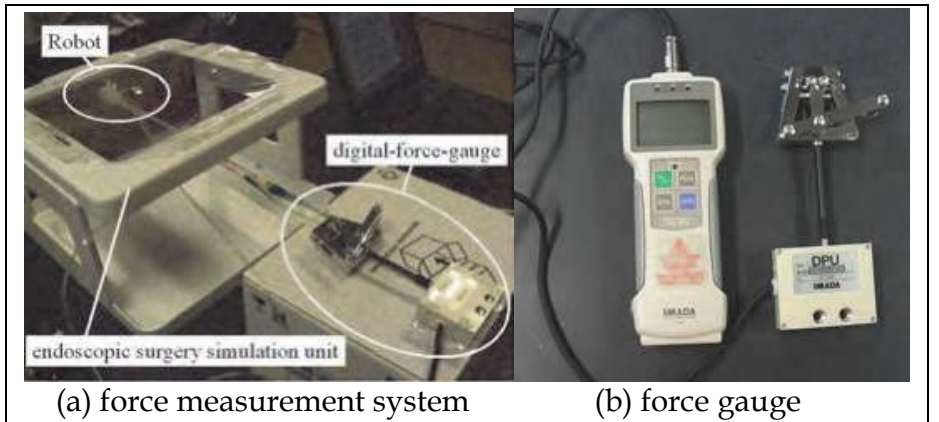

Fig. 8. Experiment setup for force measurement

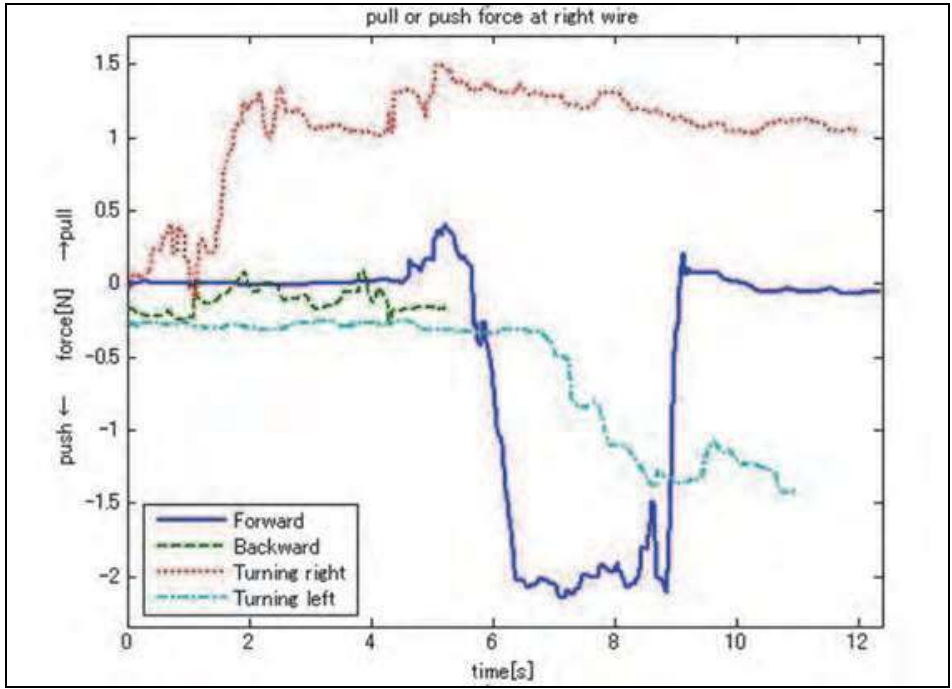

Fig. 9. Force required to manipulate wire-r in phase 1.

Fig. 9 shows the output of the force gauge and the output of force which the wire $R$ undergoes at the time of each operation. The following formulas were used in order to represent graphically.

$$
\begin{aligned}
& \left.\mathrm{F}_{\mathrm{i}}=\underset{\text { pull }}{\mathrm{F}_{\text {push }}\left(\left|\mathrm{F}_{\text {max }}\right|>\left|\mathrm{F}_{\text {min }}\right|\right)}<\left|\mathrm{F}_{\text {min }}\right|\right) \\
& \mathrm{F}=\frac{1}{3} \sum_{\mathrm{i}=1}^{\mathrm{n}} \mathrm{F}_{\mathrm{i}} \text { (i:trial number) }
\end{aligned}
$$

Fig. 10 shows the force measured in forward, backward and turning right and left motions, respectively. Fig. 10 showed that force required for operation was $5 \mathrm{~N}$ at the maximum. From the above result, we determined that we connect the actuator which outputs the force more than $5 \mathrm{~N}$ to each 6 operating portions. 


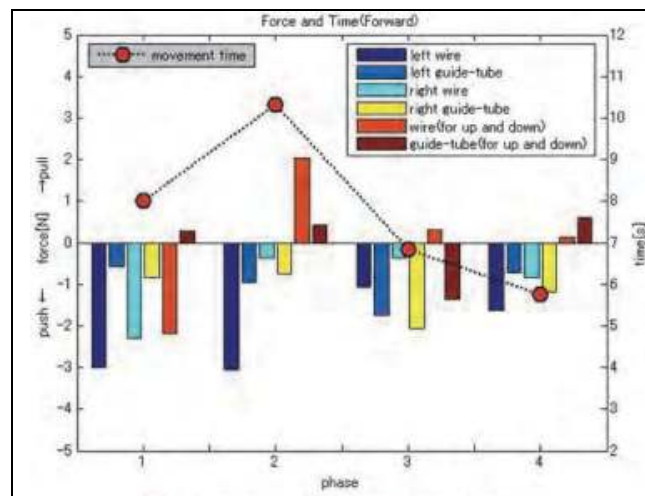

(a) moving forward motion

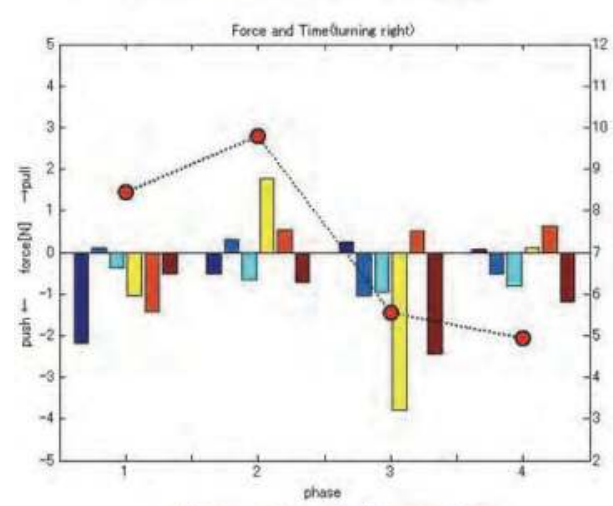

(c) turning right motion

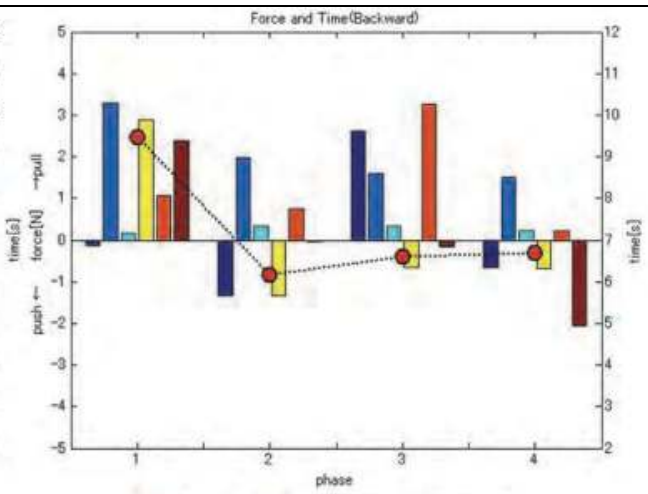

(b) moving backward motion

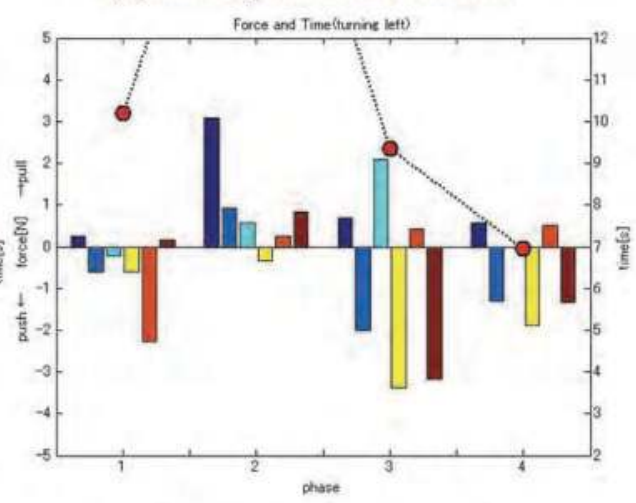

(d) turning left motion

Fig. 10. Force and time required for each motion

\subsubsection{A mechanism to realize the linear motions for manipulating wire and guide-tube pairs}

As shown in the last section, the robot motion could be realized by pulling or pushing the wire and guide-tubes to change the relation length between them. The requirements to the mechanism is: linear motion, with big stroke and a certain level of force ( around $5 \mathrm{~N}$ ) .

In this research, stepping motor with timing belt and pulley were employed as the main mechanism. The stepping motor selected is shown in Fig. 11, and the specification is shown in Table 1.

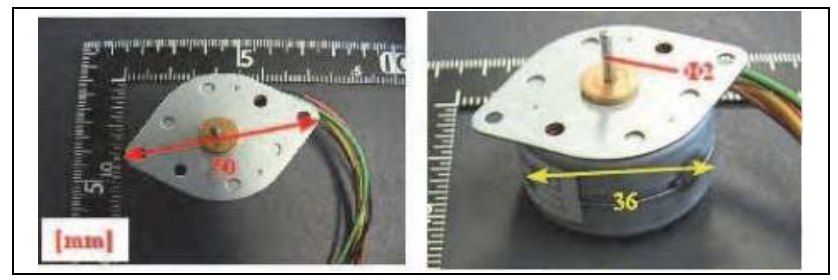

Fig. 11. Selected stepping motor (35L048B-2U,Servo Supplies Ltd) 


\begin{tabular}{|c|c|}
\hline Step angle & $7.5[\mathrm{deg}]$ \\
\hline Hold torque & $2.5[\mathrm{Ncm}]$ \\
\hline Rotor inertia & $0.04\left[\mathrm{kgcm}^{2}\right]$ \\
\hline Resistance & $64[\Omega]$ \\
\hline Current & $0.18[\mathrm{~A}]$ \\
\hline Voltage & $12[\mathrm{~V}]$ \\
\hline Inductance & $40[\mathrm{mH}]$ \\
\hline Mass & $88[\mathrm{~g}]$ \\
\hline
\end{tabular}

Table 1. Stepping motor's specification

The reason for selecting the stepping motor from various motors is that a stepping motor has the following features:

- $\quad$ Easy to control, as compared with other motors.

- Sufficiently high positioning accuracy.

- Position detection without an additional encoder.

The selected timing belt and pulley are shown in Table 2, Fig. 12 and 13.

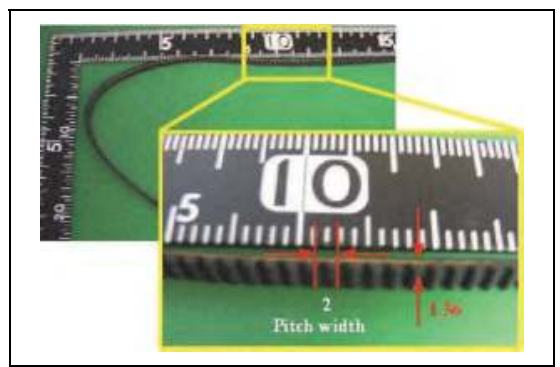

Fig. 12. Selected timing belt

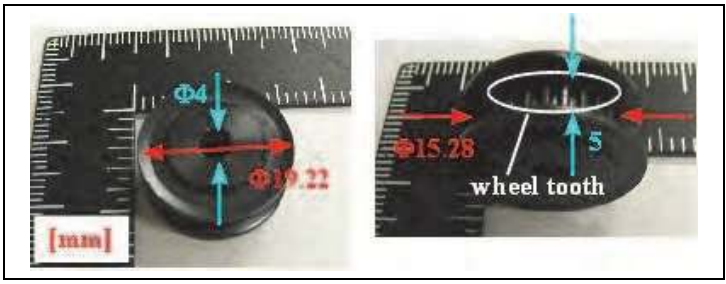

Fig. 13. Selected timing pulley

\begin{tabular}{|c|c|}
\hline Number of teeth & 24 \\
\hline Pitch & $2.0[\mathrm{~mm}]$ \\
\hline Inside diameter & $20[\mathrm{~mm}]$ \\
\hline Belt width & $9[\mathrm{~mm}]$ \\
\hline Timing belt's length & $800[\mathrm{~mm}]$ \\
\hline
\end{tabular}

Table 2. Specification of selected timing belt and pulley 
Moreover, the linear distance per rotation [mm/step] (positioning accuracy) could be determined by the following formula 3 .

$$
x=\frac{\theta \times P}{360}
$$

Where, $\mathrm{x}$ stands for the linear moving distance, $\theta$ represents rotation angle, and $\mathrm{P}$ is the product of pulley's pitch and number of teeth. Therefore, considering the specification of selected motor and pulley (see Table 1 and 2), the positioning accuracy of the combined system is \pm 1 [mm].

The mechanical system designed to realize the linear motion of wires and guide-tubes is shown in Fig. 14. The dimension of this device is summarized as follows: full length 480 [mm], height $100[\mathrm{~mm}]$, and stroke of the wire or tube 376 [mm].

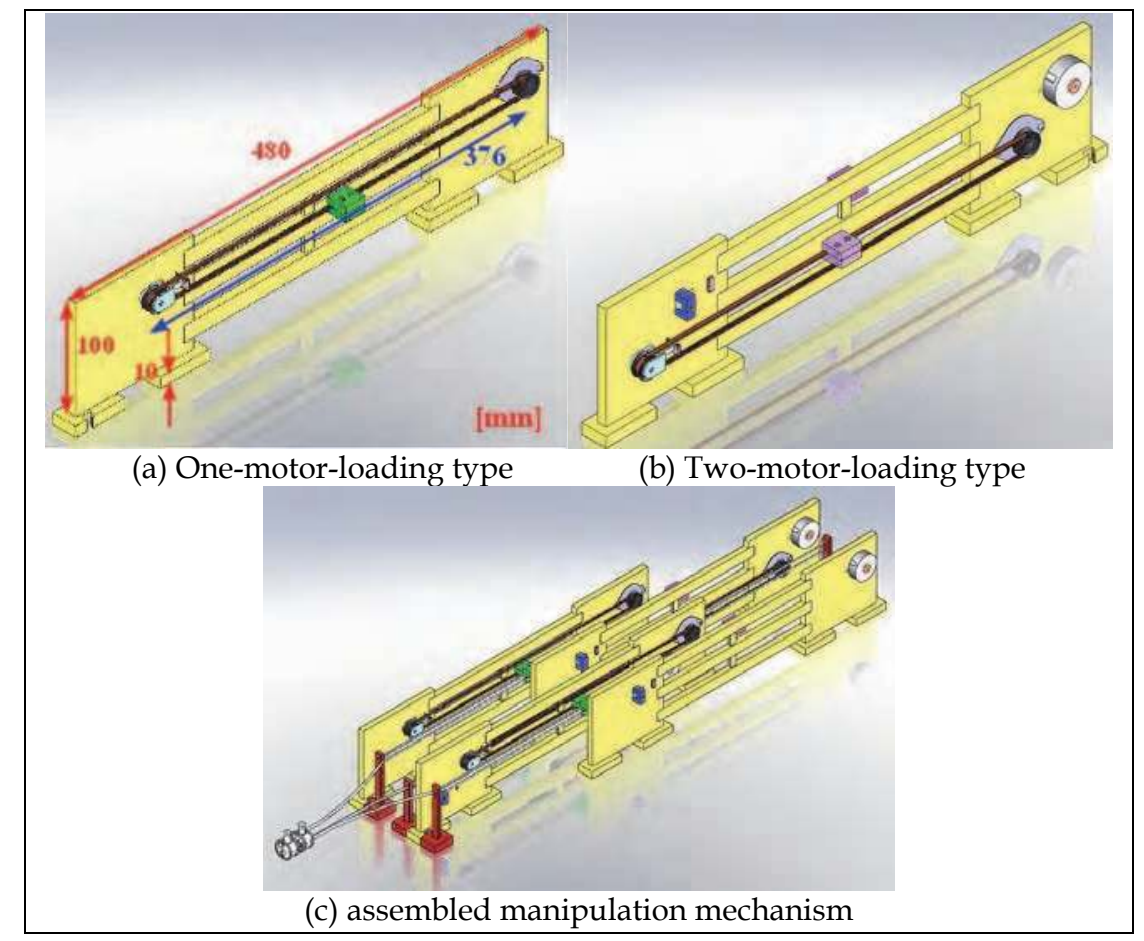

Fig. 14. Designed manipulation mechanism

In order to guarantee independent linear motion of paired wire and guide-tube to be coaxial, special consideration is given to the setting of motor-loading stands, and the mounting position of the gripping mechanism.

Two types of motor-loading stands were designed. In the one-motor-loading type (Fig. 14(a)), one motor was loaded on only one side, while in the two-motor-loading type, motors were load on both sides, one for each side. The grip mechanism could be mounted either on the upper side or the lower side of the timing belt. Two gripping parts, one mounted on the upper side, another one mounted on the lower side, from two different stands will be put to face each other for manipulating one wire and guide-tube pair. 
The motor loading position (height from the horizontal plane) was decided so that the paired gripping parts have the same height. Through adjusting the positions of paired stands, paired wire and guide-tube can be manipulated in a coaxial manner.

\subsubsection{Gripping mechanism}

In order to transmit the force from the linear mechanism to the wires and guide-tubes, a gripping mechanism that is able to hold the wires and guide-tubes steadily and attach to the timing belt should be designed. Moreover, because the timing belt is made of rubber, deflection is likely to happen. Thus, it's necessary to consider the following factors in the development of the gripping mechanism:

- To have teeth that have the same pitch with, in turn, mesh with timing belt;

- To have self-support against the deflection due to weight of the part;

- To hold the wires and guide-tubes to avoid the wires and guide-tubes' fleeing away from the gripping.

Fig. 15 shows the parts designed to realize the gripping mechanism. These parts have a $\Phi 3.0$ $\mathrm{mm}$ hole for guide-tube and a $\Phi 0.8 \mathrm{~mm}$ hole for wire, and two $\Phi 2.5 \mathrm{~mm}$ up and down for long sliding shaft. Moreover, the teeth in the parts could enable gripping mechanism to

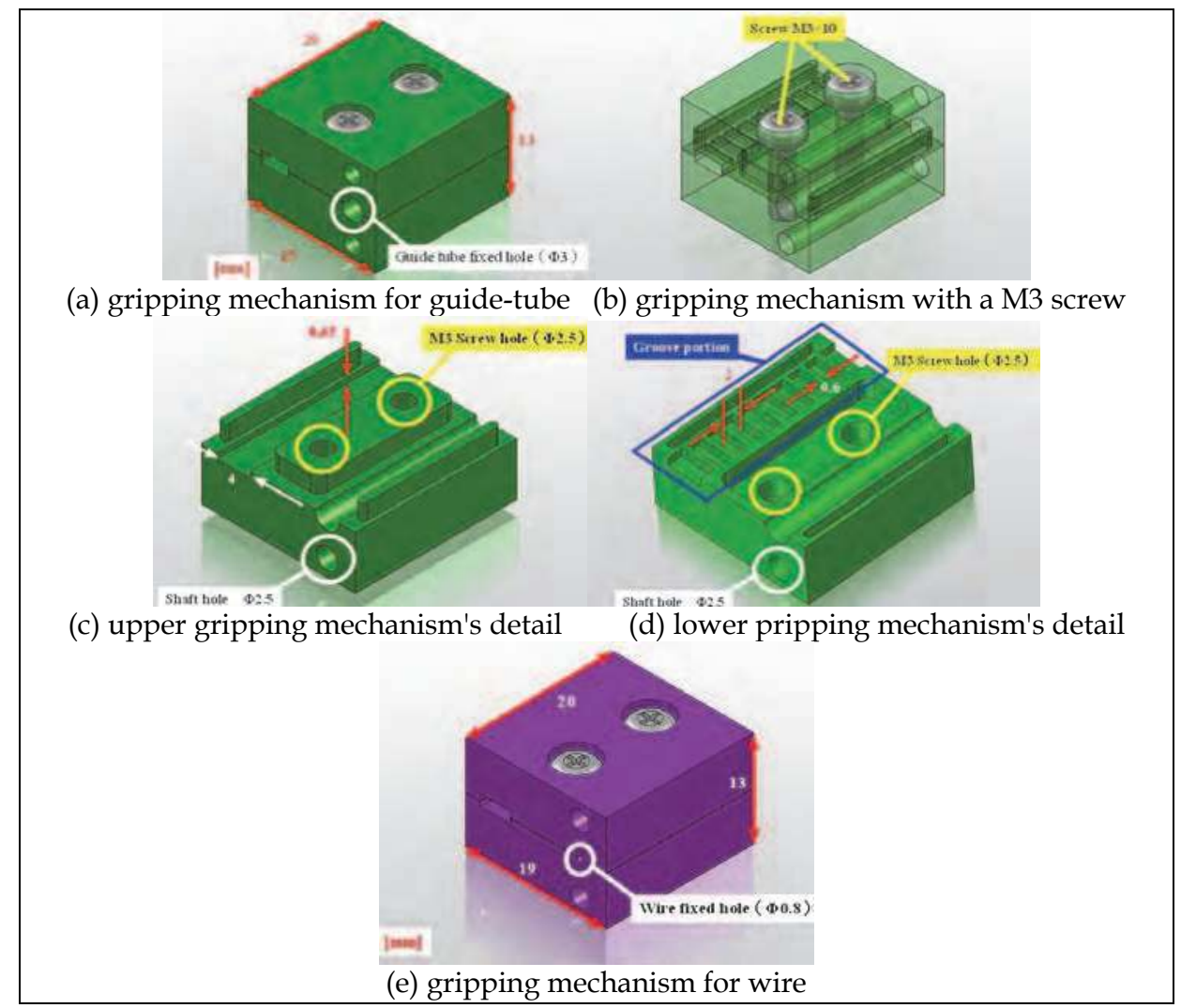

Fig. 15. Parts for realizing the gripping mechanism 


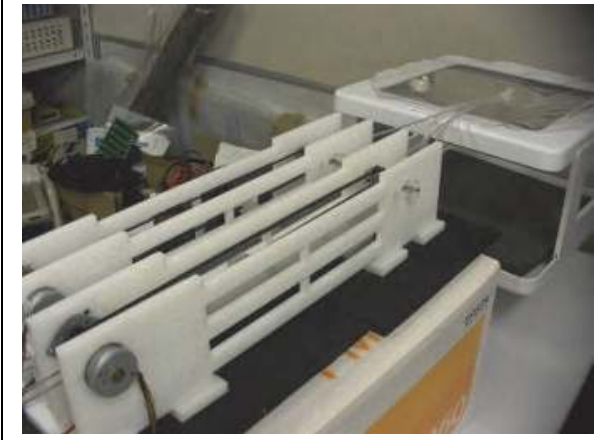

(a) A side view of the assembled device
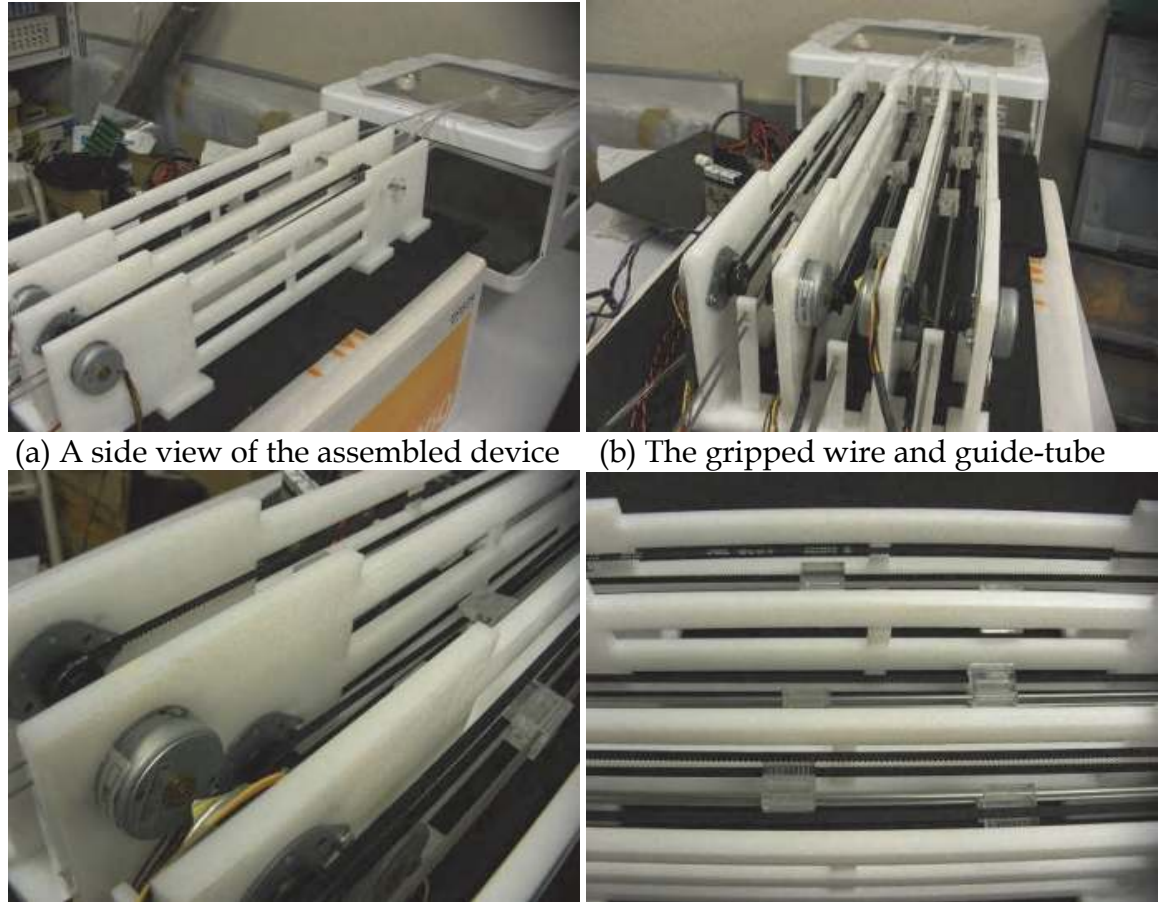

(b) The gripped wire and guide-tube

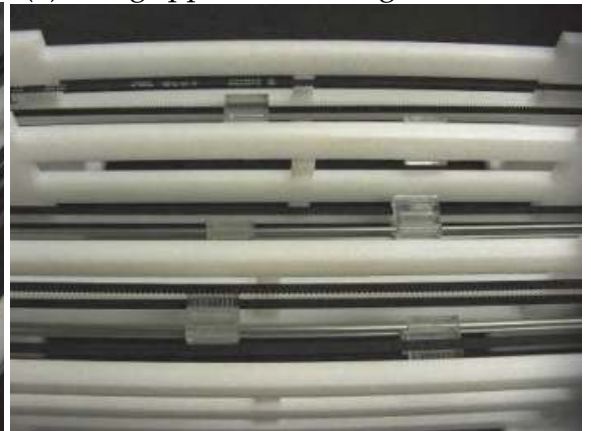

(c) Motor and timing belt fixture

(d) Gripping mechanism and timing belt

Fig. 16. Assembled WGL controller

mesh with the timing belt. And, two screws shown in Fig15(b) could prevent the wire and guide-tube from fleeing away from the gripping mechanism. Moreover, in Fig. 15, a green part is the gripping mechanism for the guide-tube, and a purple part is the gripping mechanism for the wire.The assembled WGL controlling device is shown in Fig. 16.

\subsubsection{Sensors for automatic control}

As shown in Fig. 3, the robot control system could be divided into two independent control parts: suction control of suction cups and position control. Detection of the adsorption state is realizable by using the pressure sensor of the solenoid valve. The position of two housings could detected using a magnetometric sensor. Magnetometric sensor used: trakSTRAR [Model130 and Ascension Technology Corporation] is shown in Fig. 17, and the specification is shown in Table 3. Although the range of detection is a sphere with a radius of 30 [cm], it should be sufficient to cover the abdominal cavity. The block diagram of the control system using this magnetometric sensor is shown in Fig. 18. 


\begin{tabular}{|c|c|}
\hline Size & $\Phi 1.5 \times 7.7[\mathrm{~mm}]$ \\
\hline Sampling rate & $20-255[\mathrm{~Hz}]$ (Default 80[Hz]) \\
\hline Axis & 6 Axis (Position 3 Axis and Direction 3 Axis) \\
\hline Measurement position range & $\begin{array}{c}\text { azimuth and roll: } \pm 180[\mathrm{deg}] \\
\text { elevation: } \pm \text { 90 [deg] }\end{array}$ \\
\hline Measurement angle range & $\begin{array}{c}\text { position: } 1.4[\mathrm{~mm} \text { RMS] } \\
\text { direction: } 0.5[\mathrm{deg} \text { RMS] }\end{array}$ \\
\hline Static accuracy & $\begin{array}{c}\text { position: } 0.5[\mathrm{~mm} / 305 \mathrm{~mm}] \\
\text { direction: } 0.1[\mathrm{deg} / 305 \mathrm{~mm}]\end{array}$ \\
\hline Static resolution & $\begin{array}{c}\text { coordinate value of } \mathrm{x}, \mathrm{y} \text { and } \mathrm{z}, \\
\text { azimuth, rotation number }\end{array}$ \\
\hline Output & USB1.1/2.0 or RS-232 \\
\hline Interface & Binary \\
\hline Data format & WindowsAPI, driver \\
\hline Correspondence &
\end{tabular}

Table 3. Magnetometric sensor's specification

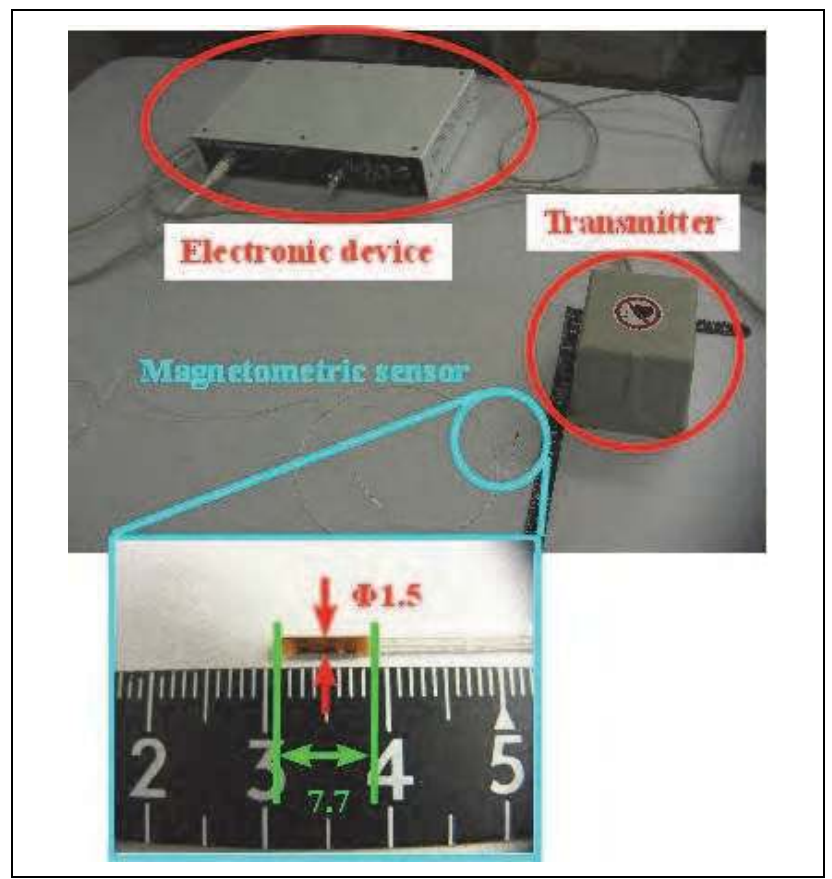

Fig. 17. Magnetometric sensor (Model130, Ascension Technology Corporation) 


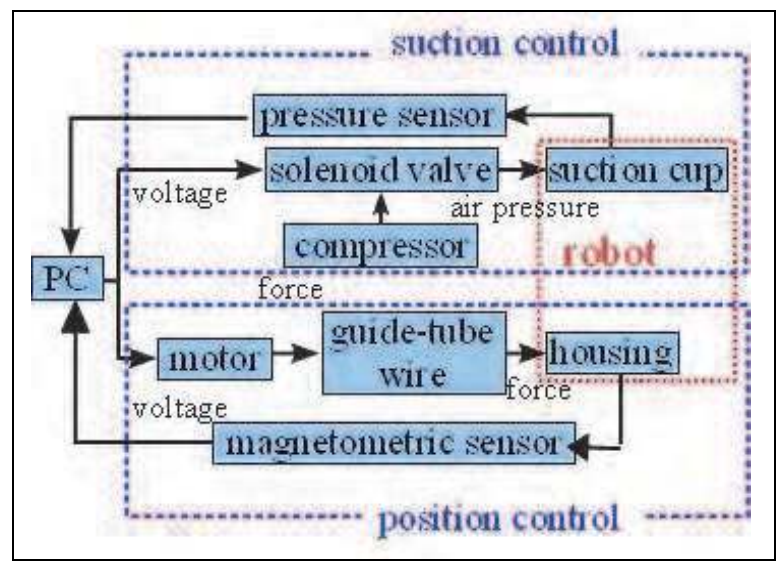

Fig. 18. Block diagram including the magnetometric sensor

\subsection{Control algorithm}

In this paper, only the control algorithm for moving forward motion is explained in detail, because the other motions could be realized by modifying the algorithm. As shown in the phase transition diagram of the moving forward motion in Fig. 4(a), the sensors to detect the end of four phases differ from each other. Position sensing is required for the end of Phase1 and 3, and adsorption sensing is required for the end of Phase 2 and 4 . The automatic control algorithm could be considered for each phase independently.

- $\quad$ Phase 1

Phase1 is for the movement of the front suction cup (see Fig. 4(a)). Fig. 19 is an illustration of the movement, where $x_{0 f}$ expresses the initial position of the front suction cup, $x_{0 r}$ expresses the initial position of the rear suction cup, $x_{\mathrm{f}}$ means the position of the present front suction cup and $x_{A}$ stands for the target position of the front suction cup. The distance from the initial position of the front suction cup to the target position is shown with the following formula 4:

$$
\mathrm{D}_{\mathrm{f}}=\left|\mathrm{x}_{\mathrm{A}}-\mathrm{x}_{0 \mathrm{f}}\right|
$$

Let the tolerance of the target position be \pm a, then an end judge function of Phase 1 could be defined by formula 5 :

$$
\mathrm{g}=\mathrm{x}_{\mathrm{f}}-\mathrm{x}_{0 \mathrm{f}}-\mathrm{D}_{\mathrm{f}}
$$

According to the value of the judge function $g$, the rotation of the stepping motors for Wire $\mathrm{L}, \mathrm{R}, \mathrm{U}$ ( left, right, up-down wire respectively) were determined. That is, the robot would keep moving until $|\mathrm{g}|<\mathrm{a}$. In the case $\mathrm{g}<0$, the motor would rotate to move forward, while in the case $g>0$, i.e., the case that the front suction cup goes over its target, the motor would rotate to move backward. 


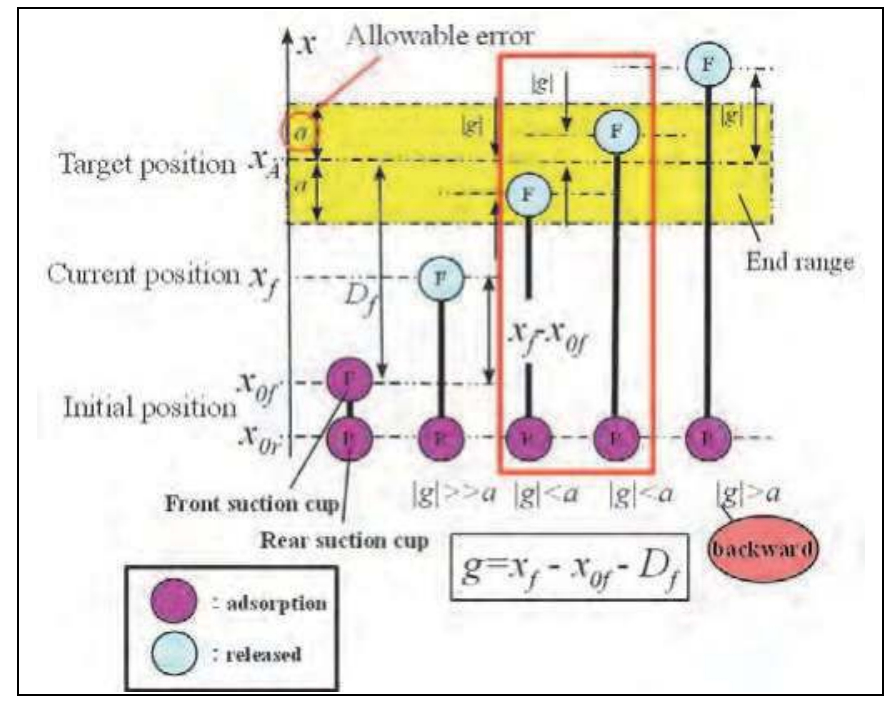

Fig. 19. An illustration for the moving forward motion in Phase 1

- $\quad$ Phase 2

The purpose of Phase 2 is to make the front suction cup adsorbed to its moving surface. Although through the solenoid valve, the deaeration (for adsorption state) or insufflation (for release state) could be controlled, the deaeration could not gurantee the adsorption of the front suction cup, i.e., only if the the suction cup is brought close enough to the moving surface, and the plane of the suction cup surface is almost parallel to the moving surface, then the deaeration could result in adsorption state. Then, the vertical up/down motion illustrated in Fig. 5 becomes important. This motion would be repeated until the front suction cup adsorbs to the moving surface. For each Wire U operation, the adsorption state would be confirmed by investigating the output of the pressure sensor of solenoid valve (formula 6).

$$
\mathrm{V}_{\text {output }}=\left\{\begin{array}{l}
0 \mathrm{~V}: \text { Adsorption } \\
6 \mathrm{~V}: \text { Release }
\end{array}\right.
$$

- $\quad$ Phase 3

In Phase 3, which is illustrated in Fig. 20, the rear housing (containing the rear suction cup) is moved towards the front housing. In Fig. 20, $x_{0 \mathrm{f}}$ and $\mathrm{x}_{0 \mathrm{r}}$ express the position (initial position) of the rear suction cup at the end of Phase4 (or Phase0), $x_{r}$ is the position of the present rear suction cup, $x_{1 f}$ is the position of the front suction cup at the end of Phase 1 and $\mathrm{x}_{\mathrm{B}}$ is the position of the target rear suction cup. Moreover, as in the Fig. 19, a stands for the tolerance and $D_{f}$ is defined by formula 4 , i.e., the distance of front suction cup was supposed to move. Since, if the distance for rear suction cup is set to $D_{f}$, the rear suction cup may contact the front suction cup after this phase, thus there would be no enough margin to move the rear suction cup in Phase 4, the expected moving distance for the rear suction cup is set to $D_{f} / 2$. Therefore, the end judge function of Phase 3 is defined in formula 7 .:

$$
h=x_{1 f}-x_{r}-\frac{D_{f}}{2}
$$


According to the value of the judge function $h$, the rotation of the stepping motors for Guide-tube L, R, U ( left, right, up-down wire respectively) were determined. That is, the robot would keep moving until $|\mathrm{h}|<\mathrm{a}$. In the case $\mathrm{h}>0$, the motor would rotate to move forward, while in the case $\mathrm{h}<0$, i.e., the case that the rear suction cup goes over its target, the motor would rotate to move backward.

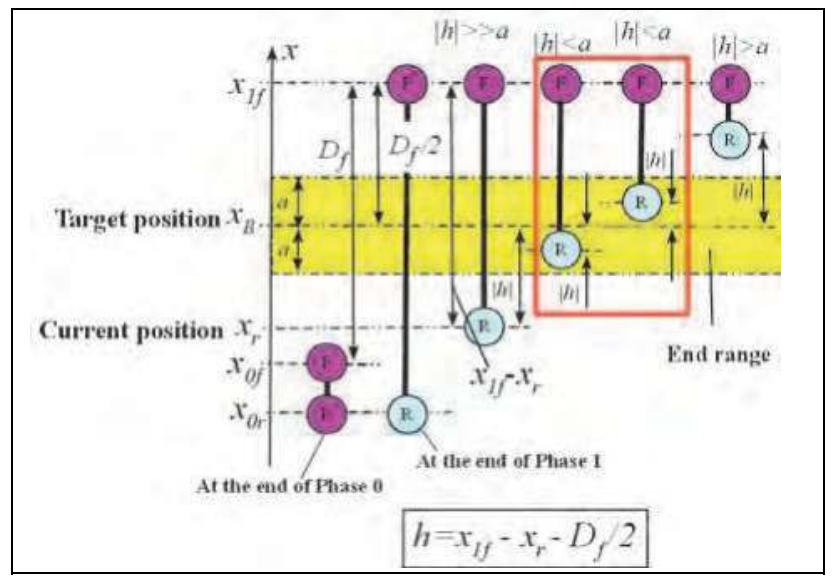

Fig. 20. An illustration for the moving forward motion in Phase 3

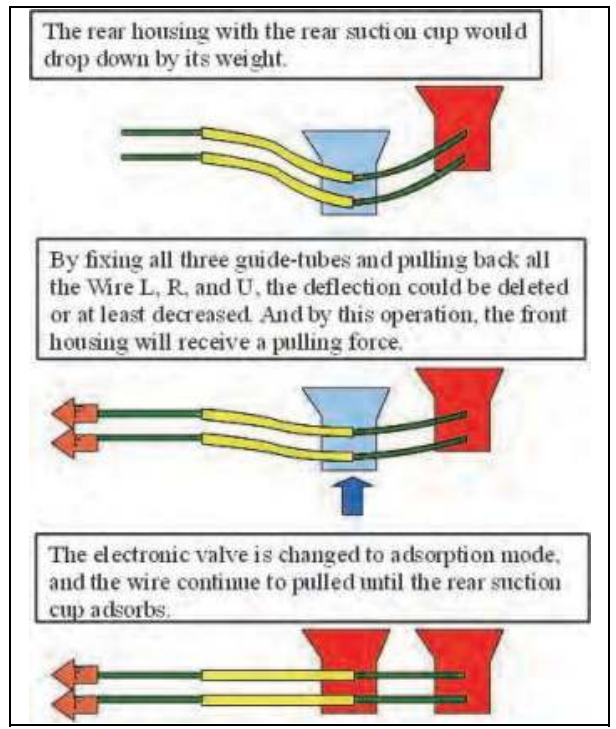

Fig. 21. The lift-up operation of the rear suction cup

\section{- $\quad$ Phase 4}

The purpose of Phase 4 is to adsorb the rear suction cup to the moving surface. Since, when released at the end of Phase3, the rear housing with the rear suction cup would drop down by its weight, there is a deflection of the wires and guide-tubes in the beginning of the Phase 
4. Basically, the operation that could lift the rear suction cup up to the moving surface is required. However, by using Wire $U$, only the front suction cup could be lifted up towards the moving surface, as shown in Fig. 5. In this study, we employed a motion shown in Fig. 21 to achieve the same effect. That is, by fixing all three guide-tubes and pulling back all the Wire $L, R$, and $U$, the deflection could be deleted or at least decreased. Certainly, by this operation, the front housing will receive a pulling force, which would affect the adsorption of the front suction cup to the moving surface. Although the experiment results would show that the feasibility of this operation, in the near future, a new mechanism should be designed improve lift-up of the rear suction cup.

Except the lift-up operation, the other sensing and operation are just the same as the Phase 2.

\subsection{The effect of parameters and experiment setting-up}

It is clear that, the two parameter $\mathrm{D}_{\mathrm{f}}$ and $\mathrm{a}$, would influence the behavior of the robot. The parameter a determines the accuracy of the robot. In the experiment, the a was set as 1.5 $[\mathrm{mm}]$, decided according to the magnetometric sensor accuracy $(1.4[\mathrm{~mm}])$, and linear motion accuracy $(1.0[\mathrm{~mm}])$. Due to the property of the robot, the $\mathrm{D}_{\mathrm{f}}$, which determines the pace of the robot motion, also affects force required for wire operation. Because the relative distance between suction cups will become large when $D_{\mathrm{f}}$ is increased, thus bending of the wire also becomes large. Thereby, at the phase of the front suction cup adsorption (Phase 2), bigger force would be needed.

On the other hand, by setting up a smaller $\mathrm{D}_{\mathrm{f}}$, the deflection could be reduced, and force needed could be kept within an allowable range. However, this would result in a slow moving speed, and a bigger influence from measurement error of magnetometric sensor. Thus, an optimal $D_{\mathrm{f}}$ has to be decided by trial and error. In the experiment, the $\mathrm{D}_{\mathrm{f}}$ was set to $10,15,20,25,30$, and 50 [mm], and movement speed was calculated for each value.

In order to verify the capacity of the developed automatic control algorithm, operation is verified using a laparoscope operation simulation unit (Fig. 6).

\section{Results of the automatic control for moving-forward motion and discussion}

In the experiment, each motion (from Phase 1-4) was taken as one step, and 3 consecutive steps were measured and recorded as a trial. During each trial, if there is a falling down from moving surface, or a deadlock due to the shortage of the torque happened, then the trial was considered as a failure.

When calculating moving speed, since the robot moves on a $x-y$ plane (ref. Fig. 23(a)), moving distance was calculated using the square root of the squared sum of distance on $x$ and y axis. The moving speed for each step and each trial (3 Steps) were calculated.

Table 4 . shows the moving speed $[\mathrm{mm} / \mathrm{s}]$ in a single trial for each $\mathrm{D}_{\mathrm{f}}$ value, and the value in brackets shows the amount of moving distance [mm] for each case.

For detailed explanation, the case of $\mathrm{D}_{\mathrm{f}}=20[\mathrm{~mm}]$ is taken as an example. In Fig. 24, the output voltage of pressure sensor is shown, where $0 \mathrm{~V}$ expresses an adsorption state, 6[V] shows a release state, and the upper and lower part of graphs depict the output of sensors for the front and rear suction cup, respectively. This graph expressed the adsorption state of the suction cup of each rear and front part. The relationship between the phase and output voltages is shown as follows. 


$$
\begin{aligned}
& \text { Phase 0: } \mathrm{Vf}=0, \mathrm{Vr}=0 \\
& \text { Phase 1: } \mathrm{Vf}=6, \mathrm{Vr}=0 \\
& \text { Phase 2: } \mathrm{Vf}=6, \mathrm{Vr}=0 \\
& \text { Phase 3: } \mathrm{Vf}=0, \mathrm{Vr}=6 \\
& \text { Phase 4: } \mathrm{Vf}=0, \mathrm{Vr}=6
\end{aligned}
$$

Where, Vf means the front output voltage, and Vr means the rear output voltage. From Fig. 24 , it is clear that, the robot could move 3 Steps without falling-down from the moving surface.

The change of the coordinate of the front and rear suction cup is shown the Fig. 25(a) and Fig. 25(b), respectively. The $x, y$ and $z$ coordinates (see Fig. 23) at the starting point were set to 0 . From the figure, it is clear that both suction cups seldomly moved in the $y$ and $z$ direction, but moved mostly in $x$ direction. Moreover, it was observed the front suction cup moved in $x$ direction about $20\left[\mathrm{~mm}\right.$ (value of $\mathrm{D}_{\mathrm{f}}$ ) in Phase1 of each step, and the rear suction cup moved more than $10[\mathrm{~mm}]\left(\mathrm{D}_{\mathrm{f}} / 2\right)$ only in Phase3 of each step. This shows that the robot is automatically manipulated, exactly following the control algorithms designed. Moreover, Fig. 26 shows the representative situations for each phase in the moving forward motion. The moving speed for the trial in the case of $\mathrm{D}_{\mathrm{f}}=20[\mathrm{~mm}]$ was $1.85[\mathrm{~mm} / \mathrm{s}]$.

Because the difference of the speed for each value of $D_{f}$ was not remarkable, the adsorption sequence of each value of $D_{f}$ was also investigated. By increasing the value of $D_{f}$, deflection of the wire becomes large and the time required for adsorption operation becomes long. Thus, a trade-off relation exists between the value of $D_{\mathrm{f}}$ and the adsorption time. Then, with each value of $\mathrm{D}_{\mathrm{f}}$, we conducted the experiment that repeats adsorption operation (Phase 2, 4) and investigated about repeatability. Moreover, we also investigated about whether adsorption time changes by increasing the value of $\mathrm{D}_{\mathrm{f}}$. In the experiment, the suction cup's adsorption state was detected per motor's a full revolution (7.5deg), and a number of motor rotation required by adsorption was measured. The greater the number of motor rotation, the longer adsorption time. The period until suction cup's adsorption is detected is set as one trial, and it is repeated 10 trials. Then, the difference (repeatability of adsorption) of each trial and the difference of the number of rotations by the value of $D_{f}$ were compared.

The result of Phase 2 is Table 5 . The value of Table 5 shows value of $D_{f}$ or the number of motor rotation required by adsorption in each trial. From Table 5 , in $\mathrm{D}_{\mathrm{f}} \leq 30$, there was no difference in the adsorption time for each value of $\mathrm{D}_{\mathrm{f}}$, and the repeatability of the adsorption operation in each trial. However, in the first trial of $D_{f}=50$, the number of rotation and time required by adsorption became twice other values of $D_{f}$. Thus, if $D_{f}$ becomes very large, deflection of the wire has various influences and has big influence on adsorption time or the reproducibility of adsorption.

Next, the rear suction cup's adsorption operation in Phase 4 of forward motion was investigated. In Phase 4, the relative distance during suction cups is adjusted by moving the rear suction cup after the front suction cup moves according to set $\mathrm{D}_{\mathrm{f}}$. For this reason, we have to set the value of $D_{f}$ and relative distance. Therefore, in each of $D_{f}=30$ (almost no influence of deflection of the wire) and $\mathrm{D}_{\mathrm{f}}=50$ (some influences of deflection of the wire), it investigated by changing relative distance with 10, 15, 20, 25, and 30 [mm]. Each relative distance and the number of motor rotation of the value of $\mathrm{D}_{\mathrm{f}}$ are shown in Table 6 . From 
Table 6, below in 25 [mm], the differences of adsorption time and the reproducibility of trial don't have relative distance. Therefore, it is considered that there is almost no influence of deflection of the wire. On the other hand, in the relative distance $30[\mathrm{~mm}]$, only in the case of $\mathrm{D}_{\mathrm{f}}=50$, the increase of number of rotation and adsorption time was confirmed. Moreover, this increase was verified in the relative distance $30[\mathrm{~mm}]$ and all the trial of $D_{\mathrm{f}}=50[\mathrm{~mm}]$. From this result, it is considered that deflection of the wire by $\mathrm{D}_{\mathrm{f}}=50$ of Phase 1 influenced not only the front but adsorption operation of the rear.

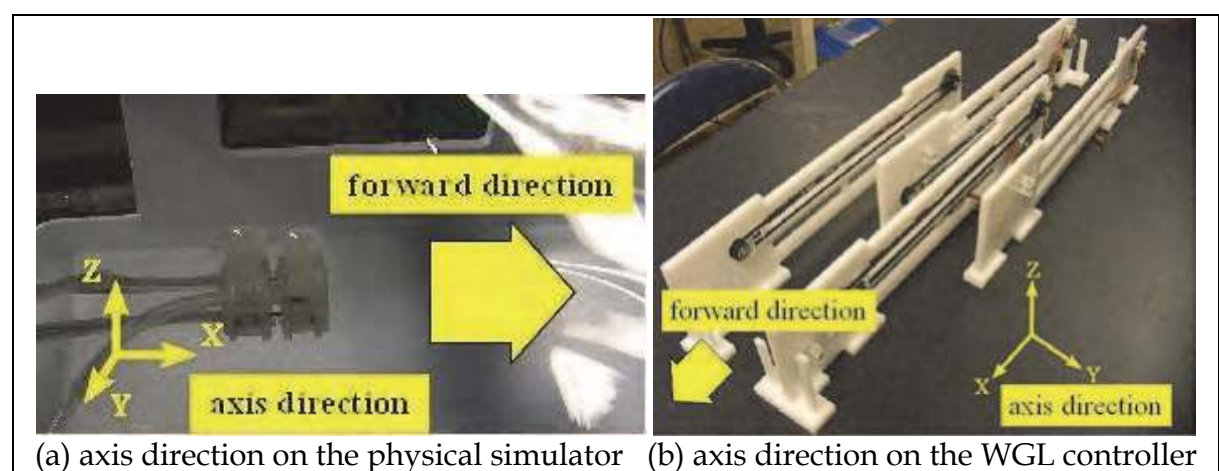

Fig. 23. Robot's move and axis direction

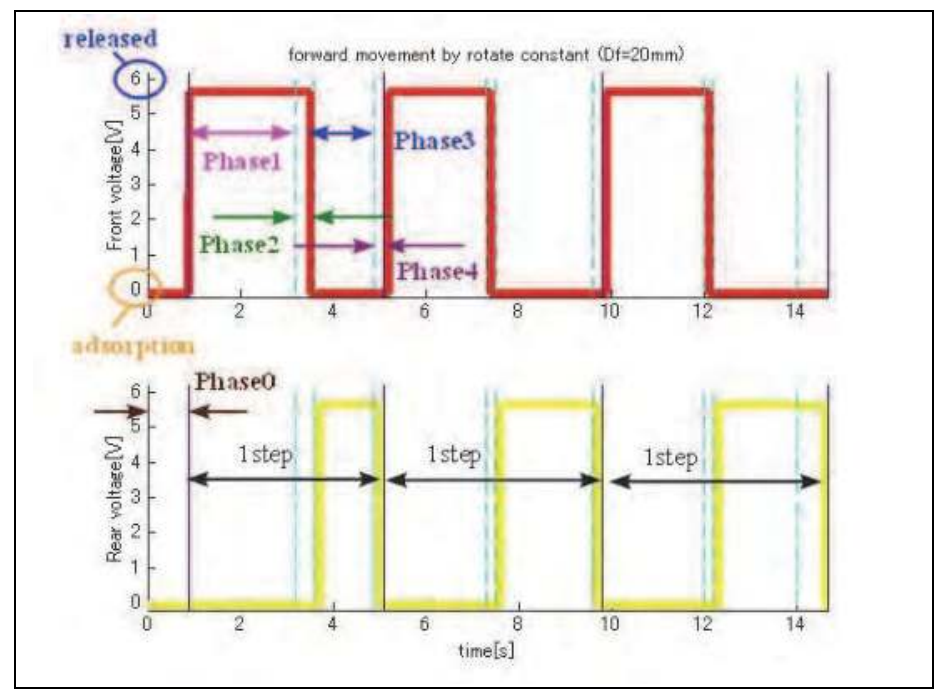

Fig. 24. The output of the adsorption switch in the unit moving distance 20 [mm] 


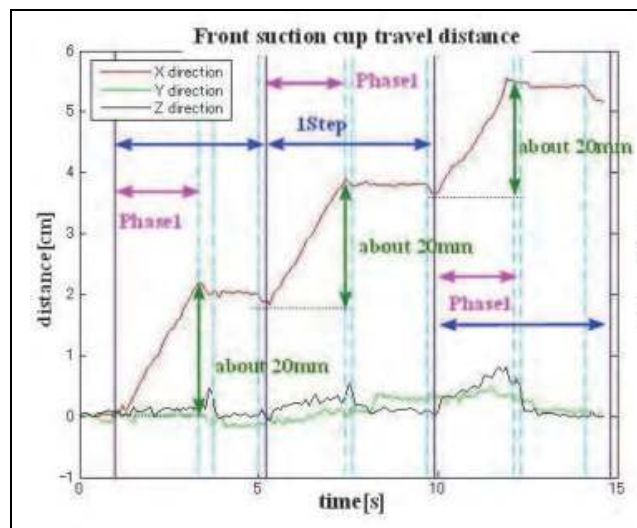

(a) front suction cup

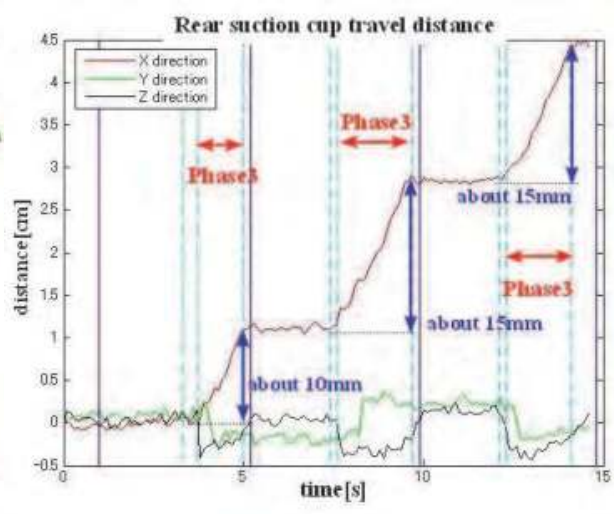

(b) rear suction cup

Fig. 25. Change of travel distance of each suction cups $\left(D_{\mathrm{f}}=20\right)$

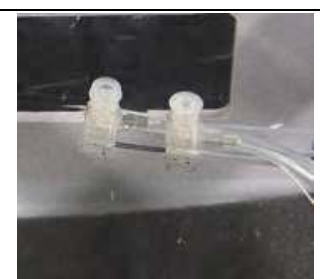

(a) phase 1

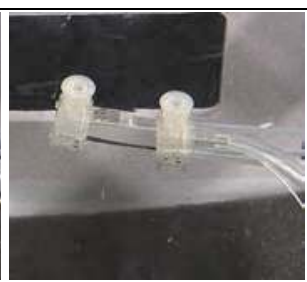

(b) phase 2

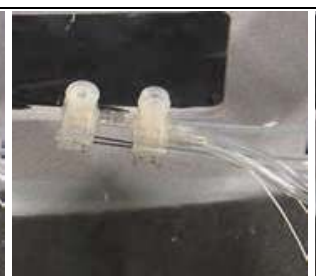

(c) phase 3

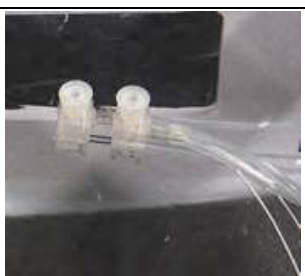

(d) phase 4

Fig. 26. Representative situations for each phase in the moving forward motion in case of $\mathrm{D}_{\mathrm{f}}$ $=20[\mathrm{~mm}]$

\begin{tabular}{|c|c|c|c|c|}
\hline $\mathrm{D}_{\mathrm{f}}[\mathrm{mm}]$ & Step 1-3 & Step 1 & Step 2 & Step 3 \\
\hline 10 & $1.86(31.11)$ & $2.54(11.41)$ & $1.70(10.73)$ & $1.65(9.09)$ \\
\hline 15 & $1.81(40.56)$ & $1.90(13.52)$ & $1.93(14.54)$ & $2.12(15.53)$ \\
\hline 20 & $1.85(51.46)$ & $2.36(19.65)$ & $2.12(19.84)$ & $1.59(15.49)$ \\
\hline 25 & $1.73(63.55)$ & $2.44(24.33)$ & $1.87(22.77)$ & $1.29(18.28)$ \\
\hline 30 & $1.94(79.78)$ & $2.70(29.05)$ & $1.70(25.83)$ & $1.77(25.92)$ \\
\hline 50 & $1.95(127.99)$ & $2.16(44.69)$ & $1.55(38.13)$ & $2.37(47.11)$ \\
\hline
\end{tabular}

Table 4 . The speed of moving-forward motion 


\begin{tabular}{|c|c|c|c|c|}
\hline $\mathrm{D}_{\mathrm{f}}[\mathrm{mm}]$ & 1st trial & 2nd trial & 3rd trial & $4-10$ trial's average \\
\hline 10 & 2 & 2 & 2 & 2 \\
\hline 15 & 2 & 2 & 2 & 2 \\
\hline 20 & 2 & 2 & 2 & 2 \\
\hline 25 & 2 & 2 & 2 & 2 \\
\hline 30 & 2 & 2 & 2 & 2 \\
\hline 50 & 4 & 2 & 2 & 2 \\
\hline
\end{tabular}

Table 5. The number of motor rotation of each value of $D_{f}$ in Phase 2

\begin{tabular}{|c|c|c|c|c|c|}
\hline relative distance $[\mathrm{mm}]$ & $\mathrm{D}_{\mathrm{f}}[\mathrm{mm}]$ & 1st trial & 2nd trial & 3rd trial & 4 -10 trial's average \\
\hline 10 & 30 & 2 & 2 & 2 & 2 \\
\hline 10 & 50 & 2 & 2 & 2 & 2 \\
\hline 15 & 30 & 2 & 2 & 2 & 2 \\
\hline 15 & 50 & 2 & 2 & 2 & 2 \\
\hline 20 & 30 & 2 & 2 & 2 & 2 \\
\hline 20 & 50 & 2 & 2 & 2 & 2 \\
\hline 25 & 30 & 2 & 2 & 2 & 2 \\
\hline 25 & 50 & 2 & 2 & 2 & 2 \\
\hline 30 & 30 & 2 & 2 & 2 & 2 \\
\hline 30 & 50 & 3 & 3 & 3 & 3 \\
\hline
\end{tabular}

Table 6. The number of motor rotation of each value of $D_{f}$ in Phase 4

\section{Conclusion}

In this paper, we described a NOTES support robot which uses suction cups and a wire driven mechanism. The robot has 3 pairs of wire and guide-tube, so it is difficult to manipulate for surgeons in operation. To realize automatic control for the robot, we developed a WGL controller, which adjusts the relative length of the wire and guide-tube pairs, and the control algorithms for it. In the experiment, it was shown that, the moving forward motion could be realized by the automatic control system.

The moving speed was also measured. From the result of Table 4, even if the value of $D_{f}$ was changed, there was no great change in the total movement speed (Step1-3), and the average moving speed was $1.86[\mathrm{~mm} / \mathrm{s}]$.

However, the moving speed $1.86[\mathrm{~mm} / \mathrm{s}]$ is not fast enough for clinical application, and improvement in speed is needed. Also, in this study, we investigated the moving forward motion. The control algorithms for other motions should be developed and verified. Furthermore, as Chapter 2 described, the robot size must be less than the over tube's inner diameter of $17 \mathrm{~mm}$ (made by TOP Corporation). Moreover, in order that the robot may correspond to various operations, it is necessary to develop in consideration of usage in laparoscopic surgery. The inner diameter of the port used by laparoscopic surgery is $12 \mathrm{~mm}$ (made by Applied Medical Resources Corporation). Therefore, as first aim, robot size less than the inner diameter of the over tube is realized, and after that, robot size less than the inner diameter of a port is realized. Finally, we have to test the whole robotic system in invivo experiment. 


\section{References}

Amy, L.; Kyle, B.; J, Dumpert.; N, Wood, A, Visty, ME, Rentschler.; SR, Platt.; SM, Farritor. \& D. Oleynikov. (2008). Surgery with cooperative robots, Computer aided surgery, Vol. 13, No. 2, pp. 95-105

Amy, L.; Nathan. W.; Jason. D.; Dmitry. O \& Shane, F. (2008). Robotic natural orifice translumenal endoscopic surgery, Proceedings of IEEE International Conference on Robotics and Automation (ICRA), pp. 2969-2974, May, 2008

Amy, L.; Nathan, W.; Jason, D.; Dmitry, O. \& Shane, F. (2008). Dexterous miniature in vivo robot for notes, Proceedings of the 2nd IEEE/RAS-EMBS International Conference on Biomedical Robotics and Biomechatronics, pp. 244-249, October, 2008

Amy, L.; Jason, D.; Nathan, W.; Lee, R.; Abigail, V.; Shane, F.; Brandon, V. \& Dmitry, O. (2009). Natural orifice cholecystectomy using a miniature robot, Surgical Endoscopy, Vol. 23, No. 2, pp. 260-266

H, Zhang.; J, Gonzalez-Gomez.; S, Chen.; W, Wang.; R, Liu.; D, Li. \& J, Zhang. (2007). A novel modular climbing caterpillar using low-frequency vibrating passive suckers, Proceedings of IEEE/ASME international conference on Advanced intelligent mechatronics, pp. 1-6, September, 2007

J, Hazey.; V, Narula.; D, Renton.; K, Reavis.; C, Paul.; K, Hinshaw.; P, Muscarella.; E, Ellison. \& W, Melvin. (2008). Natural-orifice transgastric endoscopic peritoneoscopy in humans: initial clinical trial, Surgical Endoscopy, Vol. 22, No. 1, pp. 16-20

Kai, X.; Roger, G.; Jienan, D.; Peter, A.; Dennis, Fowler. \& Nabil, S. (2009). System design of an insertable robotic effector platform for single port access (spa) surgery, Proceedings of IEEE/RSJ International Conference on Intelligent Robots and Systems, pp. 5546-5552, 2009

M, Rentschler.; J, Dumpert.; S, Platt.; S, Farritor. \& D, Oleynikov. (2007). Natural orifice surgery with an endoluminal mobile robot. Surgical endoscopy, Vol. 21, No. 7, pp. 1212-1215

M, Bessler.; P, Stevens.; L, Milone.; M, Parikh. \& D. Fowler. (2007). Transvaginal laparoscopically assisted endoscopic cholecystectomy: a hybrid approach to natural orifice surgery, Gastrointestinal Endoscopy, Vol. 66, No. 6, pp. 1243-1245

Naoki, S.; Maki, H.; Satoshi, I.; Morimasa, T.; Hajime, K. \& Makoto, H. (2010). The function which an oral type operation robot system should have, and its development, The 19th Society of Computer Aided Surgery conference special edition, Vol. 12, pp. 180-181

Satoshi, O.; Junichi. T. \& Wenwei, Y. (2009). Development of a micro mobile robot in the abdominal cavity, Proceedings of IEEE/RSJ International Conference on Intelligent Robots and Systems, pp. 4707-4711, October, 2009

Satoshi, O.; Chika, H. \& Wenwei, Y. (2010). Design and manipulation of a suction-based micro robot for moving in the abdominal cavity, Advanced Robotics, Vol. 24, No. 12, pp. 1741-1761

Satoshi, O.; Chika, H. \& Wenwei, Y. (2010). Development of a Control System for Micro Mobile Robotwith Suction Cups in the Abdominal Cavity, The 19th Society of Computer Aided Surgery conference special edition, Vol. 12, pp. 470-471

Toshiaki, H.; Satoshi, S. \& Satoshi, K. (2007). Micro switchable sucker for fixable and mobile mechanism of medical mems, Proceedings of IEEE International Conference on Micro Electro Mechanical Systems (MEMS), pp. 691-694, 2007 
W, Tierney.; D, Adler.; J, Conway.; D, Diehl.; F, Farraye.; S, Kantsevoy.; V, Kaul.; S, Kethu.; R, Kwon.; P, Mamula.; M, Pedrosa \& S, Rodriguez. (2009). Overtube use in gastrointestinal endoscopy, Gastrointest. Endosc. 70, pp. 828-834

Yoshiyuki, T.; Tomoya, N.; Emi, S.; Norihito, W.; Kazuhiro, S. \& Takashi, Y. (2010). Development of multiple degrees of freedom active forceps for endoscopic submucosal dissection, The 19th Society of Computer Aided Surgery conference special edition, Vol. 12, pp. 356-357 


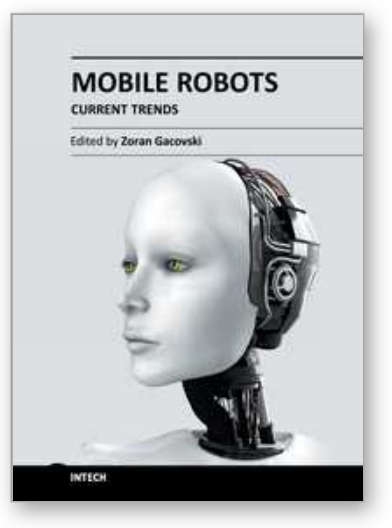

\author{
Mobile Robots - Current Trends \\ Edited by Dr. Zoran Gacovski
}

ISBN 978-953-307-716-1

Hard cover, 402 pages

Publisher InTech

Published online 26, October, 2011

Published in print edition October, 2011

This book consists of 18 chapters divided in four sections: Robots for Educational Purposes, Health-Care and Medical Robots, Hardware - State of the Art, and Localization and Navigation. In the first section, there are four chapters covering autonomous mobile robot Emmy III, KCLBOT - mobile nonholonomic robot, and general overview of educational mobile robots. In the second section, the following themes are covered: walking support robots, control system for wheelchairs, leg-wheel mechanism as a mobile platform, micro mobile robot for abdominal use, and the influence of the robot size in the psychological treatment. In the third section, there are chapters about I2C bus system, vertical displacement service robots, quadruped robots kinematics and dynamics model and Epi.q (hybrid) robots. Finally, in the last section, the following topics are covered: skid-steered vehicles, robotic exploration (new place recognition), omnidirectional mobile robots, ballwheel mobile robots, and planetary wheeled mobile robots.

\title{
How to reference
}

In order to correctly reference this scholarly work, feel free to copy and paste the following:

Chika Hiroki and Wenwei Yu (2011). A Micro Mobile Robot with Suction Cups in the Abdominal Cavity for NOTES, Mobile Robots - Current Trends, Dr. Zoran Gacovski (Ed.), ISBN: 978-953-307-716-1, InTech, Available from: http://www.intechopen.com/books/mobile-robots-current-trends/a-micro-mobile-robot-withsuction-cups-in-the-abdominal-cavity-for-notes

\section{INTECH}

open science | open minds

\section{InTech Europe}

University Campus STeP Ri

Slavka Krautzeka 83/A

51000 Rijeka, Croatia

Phone: +385 (51) 770447

Fax: +385 (51) 686166

www.intechopen.com

\section{InTech China}

Unit 405, Office Block, Hotel Equatorial Shanghai

No.65, Yan An Road (West), Shanghai, 200040, China

中国上海市延安西路65号上海国际贵都大饭店办公楼 405 单元

Phone: +86-21-62489820

Fax: $+86-21-62489821$ 
(C) 2011 The Author(s). Licensee IntechOpen. This is an open access article distributed under the terms of the Creative Commons Attribution 3.0 License, which permits unrestricted use, distribution, and reproduction in any medium, provided the original work is properly cited. 